\title{
USE OF RAY TRACING MODELING IN SHALLOW WATER ACOUSTIC SOURCE LOCALIZATION COMBINED WITH MATCHED-FIELD PROCESSING TECHNIQUES
}

\author{
Vicente Barroso Junior ${ }^{1}$, Orlando Camargo Rodríguez², \\ Carlos Eduardo Parente Ribeiro ${ }^{1}$ and Luiz Gallisa Guimarães ${ }^{1}$
}

\begin{abstract}
Underwater source localization based on acoustic modeling has been a subject of intensive research since a long time. In the case of shallow water scenarios (which are characterized by multilayered bottoms) normal-mode based acoustic propagation models are often combined with Matched-Field Processing techniques in order to provide accurate estimates of both source range and depth. This work discusses the use of a ray tracing model for source localization. Accurate predictions of the acoustic field are obtained by replacing the multilayered bottom with an equivalent (single-layer) bottom, to be used by the ray model, where the properties of the equivalent bottom are obtained through parameter optimization based on the comparison between rays (single-layer) and modes (multilayer) predictions. The accuracy of this approach is tested using data from an experiment performed by the former Undersea Research Centre of the Supreme Allied Commander Atlantic (SACLANT) in the north of the Elba Island, near the Italian coast. The results indicate that the proposed approach allows a ray model to locate an stationary source with the same accuracy as the one achieved with a normal mode model.
\end{abstract}

Keywords: underwater acoustic modeling, ray-based models, normal mode models.

RESUMO. A localização de fontes submarinas por meio de modelos de propagação acústica é um antigo problema de grande interesse científico. Em cenários de águas rasas, que se caracterizam normalmente por fundos com complexos sistemas multicamadas, os modelos de propagação baseados na teoria de modos normais são geralmente combinados com técnicas de Processamento por Campo Casado para produzirem estimativas acuradas da distância e profundidade de uma fonte acústica. 0 trabalho aqui apresentado propõe a utilização de um modelo de traçado de raios no problema da localização. De maneira a produzir estimativas acuradas do campo acústico, o modelo de raios recorre a um modelo equivalente do fundo, baseado numa escolha ótima de parâmetros, os quais são obtidos por meio da comparação entre as previsões geradas por um modelo de raios (que considera um ambiente de camada única) e as geradas por um modelo de modos (que considera um ambiente original multicamadas). A acurácia da metodologia é verificada por meio de dados adquiridos ao norte da llha de Elba (nas proximidades da costa italiana), oriundos de um experimento realizado pelo então Undersea Research Centre of the Supreme Allied Commander Atlantic (SACLANT). Os resultados alcançados indicam que a metodogia aqui proposta demonstra ser possível um modelo de raios para localizar uma fonte estática com acurácia comparável àquela tradicionalmente obtida por um modelo de modos normais.

Palavras-chave: modelagem acústica submarina, modelos de raios, modelos de modos normais.

\footnotetext{
1 Universidade Federal do Rio de Janeiro (UFRJ), Laboratório de Instrumentação Oceanográfica (LIOc), Centro de Tecnologia (CT), Bloco I, Sala 104e, Cidade Universitária, Ilha do Fundão, Caixa Postal 68.508, 21945-970 Rio de Janeiro, RJ, Brazil. Phone: +55(21) 3938-8755 - E-mails: vicente.barroso@hotmail.com; parente@peno.coppe.ufrj.br; lula@if.ufrj.br 2Universidade do Algarve (UAlg), Departamento de Física, Faculdade de Ciências e Tecnologia (FCT), Campus de Gambelas, 8005-139, Faro, Portugal. Phone: +351 289800905 - Ramal: 7633 - E-mail: orodrig@ualg.pt
} 


\section{INTRODUCTION}

Acoustic source localization can be briefly defined as the task of locating a sound source in space, relative to the position of an array of hydrophones, given a set of receptions of the sound transmitted by the source; the sound field can be described in terms of physical quantities, such as sound pressure or particle velocity. By measuring these properties it is possible to obtain an estimative of the source range ${ }^{1}$, depth and bearing ${ }^{2}$.

Despite the latest technological advances in underwater source localization (together with source tracking and classification), it still remains a challenging task due to the particular features of underwater sound propagation, especially in shallow water. The propagation regime exhibits a complex dependence on the multipath nature of propagation, which is induced by both sound refraction and sound reflection on the surface and the bottom; the propagation channel is itself frequency dependent, with ambient noise acting at different time and space scales, in addition to the reverberation and a large number of non-linear effects, which are extremely difficult to deal with.

A common localization method consists in using an acoustic model to calculate the replicas for different possible positions of the source, and producing a two-dimensional map of the comparisons of observed and predicted data fields. Generally speaking, the comparison relies on the curve fitting aim of the prediction being as similar as possible in phase and amplitude to the observation; to this end the comparison is mostly based on Matched-Field Processing (MFP) techniques. MFP basically consists in correlating data recorded on an array of hydrophones with replica predictions, calculated by a reliable acoustic model (Kuperman \& Lynch, 2004). The main goal of the acoustic model is to properly describe sound propagation in the ocean waveguide, and to generate predictions of acoustic pressure for a possible set of source ranges and depths; the point that produces the higher correlation allows to infer the true range and true depth of the source.

In general, MFP has been shown to be efficient for solving inverse problems in underwater acoustic, such as source localization; yet, modeling and inversion are bounded by an important limitation: particular care has to be taken in order to feed the model with a proper description of the environment; in fact it has been shown that localization can be extremely sensitive to model or to environmental parameter mismatch (Soares \& Jesus, 2004). Besides that, the source pressure level within the bandwidth should be high enough in order to ensure that the local signalto-noise ratio (SNR) is positive. The models of choice for MFP calculations are usually the Normal Mode Models (NMMs).
NMMs have been used in underwater acoustics for different applications. Usually, a NMM is able to handle multilayered bottoms, and therefore is able to provide accurate predictions of the acoustic field in shallow water scenarios. For such scenarios mode shapes and eigenvalues are extremely sensitive to bottom properties, which are required to be well known a priori in order for the NMM to provide accurate predictions. A limitation of NMMs is their difficulty to deal with non-flat boundaries and/or dependence of sound speed on range. Both factors can be properly handled through Ray Tracing.

The ray solution to the wave equation represents a high frequency approximation, which is based on solving the Eikonal equation to obtain the phase of the propagating wave, and solving the transport equation to obtain the wave amplitude (Rodríguez et al., 2012). Ray Tracing Models (RTMs) easily allow to incorporate the effects of variations of sound speed and boundary variations over range. Yet, the waveguide geometry imposes a frequency threshold, below which the prediction can fail, and RTMs can no handle multilayered bottoms (Etter, 2013). Even so, given the ambiguous nature of the acoustic field (when different combinations of parameters can induce the same acoustic response) there is a possibility of replacing a given multilayered bottom with an equivalent (single-layer) one, such that the RTM can be able to provide predictions, as accurate as those produced with a NMM for the original environment.

The main goal of this work is to discuss the issue of an equivalent single-layered environment, for which a RTM can provide accurate field predictions, to be used for MFP shallow water source localization. To this end simulated pressure fields calculated with a NMM are used as a reference. To find the equivalent single-layer bottom, an intensive search is carried out looking for the optimal parameters, allowing the RTM to provide predictions as accurate as those produced by the NMM. Additionally, an analysis of the role of SNR is also provided.

The reliability of the method is further tested considering acoustic data from a sea experiment, held in the north of Elba Island, Italy, performed in 1993 by former SACLANT Undersea Research Centre. The data are considered ideal for the purpose of this work because of the good knowledge of local bottom properties, for the use of a vertical array with 48 hydrophones, and because of accurate estimates of source position discussed in the literature; of additional interest was also the discussion of a global search procedure for parameter optimization based on genetic algorithms (Gingras \& Gerstoft, 1995; Soares et al., 1999). Theory,

\footnotetext{
${ }^{1}$ horizontal distance between source and receiver.

${ }^{2}$ horizontal angle, centered at the receiver point, between source and a reference direction (normally east direction with positive angles going counterclockwise)
} 
simulations, experimental data, considered acoustic models and conclusions are presented in the following sections.

\section{METHODOLOGY \\ Theoretical Revision}

Matched-Field Processing (MFP) techniques have been used in underwater acoustic since the pioneering work of Hinich (1973) and Bucker (1976). According to Baggeroer et al. (1988), MFP can be used as a parameter estimation technique for localizing the range, depth and bearing of a point source from the signal field propagating in an acoustic waveguide. MFP techniques can be also applied to a wide range of problems including the localization of static and moving sources, the determination of environmental parameters needed for accurate predictions of acoustic propagation and the evaluation of model accuracies (Tolstoy, 1993).

The principle underlying MFP is extremely simple: the acoustic pressure is measured on an array of sensors; then, an accurate acoustic model is used to compute the predicted acoustic pressure field of replicas produced by a source at a particular location in the ocean environment. Measured fields are then matched against the set of modeled fields (replica fields) by some sort of mathematical algorithm, which generates an ambiguity surface of source location candidates and, finally, the best agreement on the surface indicates the position of the source.

MFP in underwater acoustics is typically an inverse problem, and may be posed as an optimization problem, where the objective function is the MFP response to be maximized (Soares et al., 1999). In the present context, the purpose of MFP is to locate sources of acoustic energy in underwater environments. The use of an accurate and reliable acoustic model to compute the predicted acoustic pressure replicas is fundamental for successful source localization. If the ocean environment is well known and the propagation model used to produce the set of modeled fields is accurate, a good match between the measured and modeled fields should be found (Westwood, 1992).

Generally speaking, the main goal of underwater acoustic modeling is to develop a detailed description of sound propagation in the ocean waveguide through the calculation of the pressure field between a set of sources and receivers. To this end a propagation model provides an approximate solution of the wave equation, from which the time independent Helmholtz equation (a.k.a. frequency-domain wave equation) can be obtained by use of the frequency-time Fourier transform pair. In the case of a water column with a constant density, the Helmholtz equation can be written as:

$$
\nabla^{2} P(\mathbf{r}, \omega)+k^{2}(\mathbf{r}) P(\mathbf{r}, \omega)=S(\mathbf{r}, \omega)
$$

where:

- $P(\mathbf{r}, \omega)=$ acoustic pressure in the frequency-space domain;

- $k(\mathbf{r})=\omega / c(\mathbf{r})=$ wavenumber at angular frequency $\omega$ and sound speed $c(\mathbf{r})$; and

- $S(\mathbf{r}, \omega)=$ signal transmitted by the acoustic source.

Since no general solution exists that allows to account for variations of sound speed along range and depth (and/or variations of sea surface and bottom), solving the Helmholtz equation requires the development of computational methods based on different theoretical approaches; such methods can be extended in order to handle stochastic phenomena, such as scattering and reverberation. Given the broad range of variations of acoustic pressure (and the fact that it corresponds to a complex function) predictions are often discussed in terms of transmission loss (TL), which can be defined as:

$$
T L=-20 \log |P(\mathbf{r}, \omega)|
$$

Acoustic propagation models can be grouped in two broad categories: ray models (ray tracers and WKB ${ }^{3}$ models) and wave models (normal modes, fast field and parabolic approximation models).

Normal modes are analogous to the vibration modes of a string; equations for the modes can be obtained from Eq. (1) using the method of separation of variables, which leads to a differential equation for the depth-dependent functions; the corresponding solution corresponds to an infinite sum of eigenfunctions (or modes). Main advantages of NMMs include highly accurate and fast calculations at low frequencies, making them suitable for a wide range of MFP cases (Tolstoy, 1993). The NMM used in this discussion is the KRAKEN model (Porter, 1992), whose features can be summarized as follows:

- ability to handle multilayered environments;

- ability to handle elastic layers;

- availability of free, rigid, and homogeneous halfspace options for boundary conditions; and

- high-accuracy, robustness and efficiency.

${ }^{3}$ WKB: Wentzel, Kramers, and Brillouin; a.k.a. WKBJ: Wentzel, Kramers, Brillouin, and Jeffreys. 
Ray theory, on the other hand, is derived as the asymptotic limit solution (infinite frequency) to Eq. (1), assuming that the sound speed varies gradually on scales relative to actual source wavelength. It may be interpreted as a combination of the WKB theory, and of the method of stationary phase. By dividing the medium into arbitrarily small layers the formalism effectively leads to ray refraction according to Snell's law. Advantages of ray solutions are that they can be rapidly computed, are highly intuitive, and are easily visualized; ray tracing models also allow to incorporate, in a easy way, the effects of variations of sound speed and boundary variations over range. However, ray theory can not account for diffraction effects and general low frequency behavior (Tolstoy, 1993; Jensen et al., 2011); ray tracing is also unable to handle multilayered environments. Another drawback of ray models is related to the breakdown of the solution in the vicinity of focal points and caustics; such breakdowns can be avoided by substituting the transport equation with the dynamic equations of Gaussian beams (Rodríguez et al., 2012).

According to Tolstoy (1993), the ray theoretic approach is rarely used in MFP because of the corresponding relevance of low frequency propagation. However, given the ambiguous nature of the acoustic field (when different combinations of parameters can induce the same acoustic response) there is a possibility of replacing a given multilayered environment with an equivalent (single-layer) one, allowing a RTM to produce predictions as accurate as those produced with a NMM for the original environment. The RTM used in this discussion is the TRACEO model (Rodríguez et al., 2012), which allows to:

- consider the presence of objects between a source and a receiver;

- calculate a broad range of physical quantities, such as ray trajectories, eigenrays, arrivals and amplitudes, coherent acoustic pressure and particle velocity;

- account for range-dependent boundaries, such as wavy surfaces, complex bathymetries, source speed profiles and fields; and

- account for boundary shear properties.

A key point in source localization is to rely on a mathematical tool (a.k.a. estimators, or processors) to compare observed and predicted data. The Bartlett estimator was chosen due to its simplicity of implementation and because of its previous application to the data processing of the North Elba Sea experiment; for instance, Gingras \& Gerstoft (1995) used the Bartlett processor at a single frequency for source localization; later, Gerstoft \&
Gingras (1996) relied on the processing of several frequencies to improve the robustness of estimation. The Bartlett processor can be defined as (Soares \& Jesus, 2004):

$$
B(\Theta)=\frac{1}{N} \sum_{n=1}^{N} \mathbf{p}^{\mathbf{H}}\left(\Theta, \omega_{n}\right) \widehat{\mathbf{C}}_{x x}\left(\omega_{n}\right) \mathbf{p}\left(\Theta, \omega_{n}\right),
$$

where:

- $B(\Theta)=$ Bartlett processor;

- $\boldsymbol{\Theta}=$ vector of parameters, for which $B(\Theta)$ is to be optimized;

- $N=$ number of frequencies;

- $\mathbf{p}\left(\Theta, \omega_{n}\right)=$ replica vector (i.e., the model prediction);

- $\mathbf{p}^{\mathbf{H}}\left(\Theta, \omega_{n}\right)=$ Hermitian transpose of the replica vector p;

- $\widehat{\mathbf{C}}_{x x}\left(\omega_{n}\right)=$ estimate of the Correlation Matrix of the measured acoustic field; and

- $\omega_{n}=$ angular frequency.

Notice that to in order to ensure that $\max [B(\Theta)]=1$, the replica and observation vectors should be normalized. For a single frequency, Eq. (3) becomes:

$$
B(\Theta)=\mathbf{p}^{\mathbf{H}}(\Theta) \widehat{\mathbf{C}}_{x x} \mathbf{p}(\Theta) .
$$

The estimate of the Correlation Matrix can be calculated as (Rodríguez et al., 2009):

$$
\widehat{\mathbf{C}}_{x x}=\frac{1}{L} \sum_{n=1}^{L} \mathbf{d}_{n} \mathbf{d}^{\mathbf{H}}{ }_{n},
$$

where:

- $L=$ number of snapshots (field observations collected over a given time interval);

- $\mathbf{d}=$ measured data; and

- $\mathbf{d}^{\mathbf{H}}=$ Hermitian transpose of the measured data $\mathbf{d}$.

An ambiguity surface is then obtained by generating predictions of the pressure field (replica vectors $\mathbf{p}$ ) for different possible source locations, and by comparing them to the observations (vector d). According to Baggeroer et al. (1988) the signal observed at an array is contaminated with additive, spatially correlated noise, that propagates in the same ocean environment as the signal. When the SNR is low, signal extraction can be optimized 
by taking advantage of the physics of both the signal and noise structure, which must then be coupled to the specific methods of signal processing. Yet, noise is not the only problem; estimates of source localization can be significantly degraded by issues of low signal sampling (insufficient hydrophones, reduced signal bandwidth, etc.), and by uncertainties in array positioning or environmental data (Tolstoy, 1993). Different studies of matched-field localization in shallow water have shown that a satisfactory estimate of source range and depth can be found with low SNR when broadband signals are used. In general, with SNR $<-10 \mathrm{~dB}$, successful source localization with narrowband signals tends to be rare.

In this sense the remarkable quality of the data from the North Elba Sea Experiment represents an ideal reference for the purpose of the work presented here, as will be described in the next section.

\section{The North Elba Sea Experiment}

In 1993, the former Supreme Allied Commander Atlantic (SACLANT) Undersea Research Centre conducted a sea trial in the Mediterranean Sea, in a shallow water area in the north of the Elba Island, off the Italian west coast (see Fig. 1); the site was chosen because environmental conditions were known from earlier SACLANT Centre experiments (Gingras, 1994; Gingras \& Gerstoft, 1995).

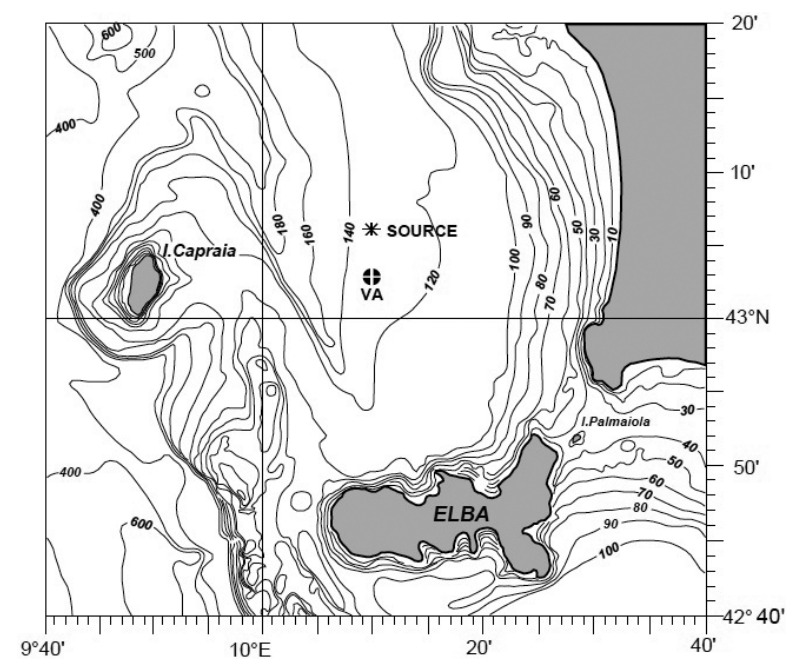

Figure 1 - Sea trial site: "VA" indicates the position of the vertical array and the source position is represented by an asterisk (adapted from Gingras, 1994).

The objective of the experiment was to collect data on a vertical array in shallow water for verifying the performance of geoacoustic and geometric parameter estimation methods based on the inversion of acoustic field observations. The experiment employed an array that spanned most of the water column, a station- ary and a moving source. There was also an accurate knowledge of hydrophone positions via active array positioning, and a priori knowledge of the geoacoustic parameters. The trial was conducted in a flat shallow water area, along a track running parallel to the isobaths; the propagation conditions were typical of downward refracting summer sound speed. The experimental site is characterized by a bottom covered with clay and sand-clay sediments (Gingras \& Gerstoft, 1995; Gerstoft \& Gingras, 1996).

On the first day of the experiment, a vertical array containing 48 hydrophones at $2 \mathrm{~m}$ spacing (with a total aperture of $94 \mathrm{~m}$ ) was deployed at a site of measured bathymetry of $128 \mathrm{~m}$ (Gerstoft \& Gingras, 1996). So, the signal to be analyzed in this study contains 48 channels with 65536 samples each one along approximately 1 minute of recordings. The sampling frequency was $1 \mathrm{kHz}$ and the Fast Fourier Transform (FFT) block-size consisted of 1024 points (Soares et al., 1999).

A stationary remote controlled moored acoustic source (RECMAS) type HX-90G was deployed at a depth of $80 \mathrm{~m}$, connected to a buoy in a distance of about $5.6 \mathrm{~km}$ to the north of the array. At the source location the bathymetry was measured to be $130 \mathrm{~m}$. Different signals were transmitted at frequencies of 170 and $335 \mathrm{~Hz}$, not simultaneously. The signal transmitted to be analyzed in this study is a continuous transmission of pseudorandom noise (PRN) produced using a maximal length sequence (MLS) with a bit length of 20 ms modulated onto a carrier with a center frequency of $335 \mathrm{~Hz}$, the repetition length was $1.3 \mathrm{~s}$, and the $-3 \mathrm{~dB}$ bandwidth of $30 \mathrm{~Hz}$ (Gingras, 1994; Gingras \& Gerstoft, 1995; Gerstoft \& Gingras, 1996). Despite the common reference in the literature to the frequency of $335 \mathrm{~Hz}$, careful analysis of the spectra of the recorded signals points to a value of $331 \mathrm{~Hz}$, which is the one considered in this work.

A baseline environmental model was established for the north Elba site from a variety of references (Gerstoft \& Gingras, 1996). The environmental model consisted of an ocean layer overlying a sediment layer and a bottom layer. All layers were assumed to be range-independent. The water sound speed profile was a summer profile, almost isovelocity down to $60 \mathrm{~m}$, followed by a strong thermocline extending to $80 \mathrm{~m}$ depth. Sediment and bottom parameters of the baseline model are average parameters determined from transmission loss curves in the North Elba basin, yet not at the exact site of the experiment (Gingras, 1994). The baseline environmental model is illustrated in Figure 2.

In order to establish a proper reference with the discussion presented in the literature, the bottom parameters considered are those from Gingras \& Gerstoft (1995), obtained through genetic algorithms (GA) optimization, which are indicated in Table 1. 


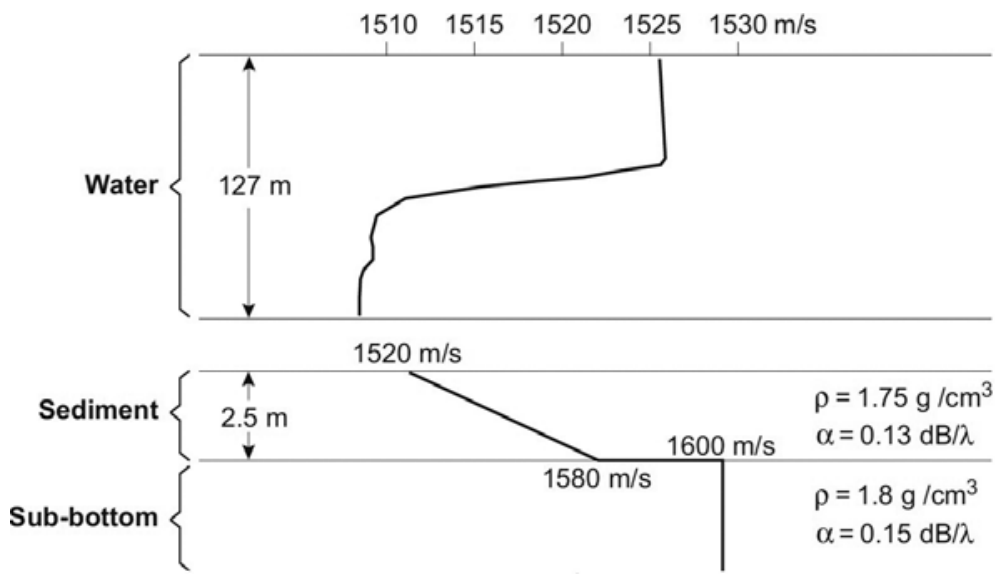

Figure 2 - Sound speed profile and historical geoacoustic average parameters considered in the North Elba Sea Experiment (from Gingras, 1994; Akal et al., 1972).

Table 1 - Layer bottom properties estimated through genetic algorithms optimization (from Gingras \& Gerstoft, 1995).

\begin{tabular}{|c|c|c|c|}
\hline \multirow{2}{*}{ Properties } & Layer 1 & Layer 2 & Layer 3 \\
\cline { 2 - 4 } & (Upper layer) & (Middle layer) & (Halfspace) \\
\hline Compressional velocity $(\mathrm{m} / \mathrm{s})$ & 1505 & 1556 & 1576 \\
Density $\left(\mathrm{g} / \mathrm{cm}^{3}\right)$ & 2.0 & 2.0 & 1.6 \\
Compressional attenuation $(\mathrm{dB} / \lambda)$ & 0.11 & 0.11 & 0.18 \\
\hline
\end{tabular}

\section{RESULTS AND DISCUSSION MFP localization with KRAKEN NMM}

The KRAKEN model was used for the calculation of replicas at the frequency of $331 \mathrm{~Hz}$ and the ambiguity surface was calculated with the Bartlett estimator for different possible positions of the acoustic source. The ambiguity surface is shown in Figure 3 and indicates that the acoustic source was located at a depth of $64 \mathrm{~m}$ and a range of $5380 \mathrm{~m}$ relative to the array. These results are validated by the literature (Gingras \& Gerstoft, 1995; Gerstoft \& Gingras, 1996).

\section{The Equivalent Environment}

As a preliminary ("naive") strategy one can consider three different configurations of bottom parameters for the idealization of the equivalent environment (see Fig. 4).

For each configuration TRACEO can produce predictions at 170 and $331 \mathrm{~Hz}$ for the set of source depths and ranges shown in Figure 3, and the Bartlett estimator can be used over all ranges and depths to compare ray and mode predictions. Corresponding results are shown in Table 2 and indicate that the source at $170 \mathrm{~Hz}$ "sees" better the halfspace (i.e., the lowest layer, bottom basement), while at $331 \mathrm{~Hz}$ the source "sees" better the middle layer; this is in good agreement with the well known fact that the lower the frequency the deeper the resolution of bottom layers. Additionally, the low values reached of the Bartlett estimator indicate that this "naive" strategy is not efficient and that the accuracy of TRACEO predictions is not satisfactory.

The parameter space can be extended in order to include the following parameters (Rodríguez et al., 2012):

- $N_{\theta}$, which is the total number of rays; and

- $\theta_{\max }$, which is the semi-aperture (i.e., half of the angle interval for which all rays are being launched).

Therefore, additional calculations were performed with number of rays, $N_{\theta}$, in an interval from 11 to 251 rays, and $\theta_{\max }=$ $30^{\circ}$. The results are shown in Table 3 and indicate that addition of $N_{\theta}$ to the parameter space allows in fact to improve the match between TRACEO and KRAKEN; the results also indicate that the higher the frequency the higher the number of rays.

The dependence of the Bartlett estimator on $N_{\theta}$ for 170 and $331 \mathrm{~Hz}$ is shown in Figure 5. In both cases one can notice that above a given $N_{\theta}$ the estimator assumes an asymptotic behavior, without significant improvements. Yet, at $170 \mathrm{~Hz}$, there is subtle difference in replacing the multilayered environment with the 


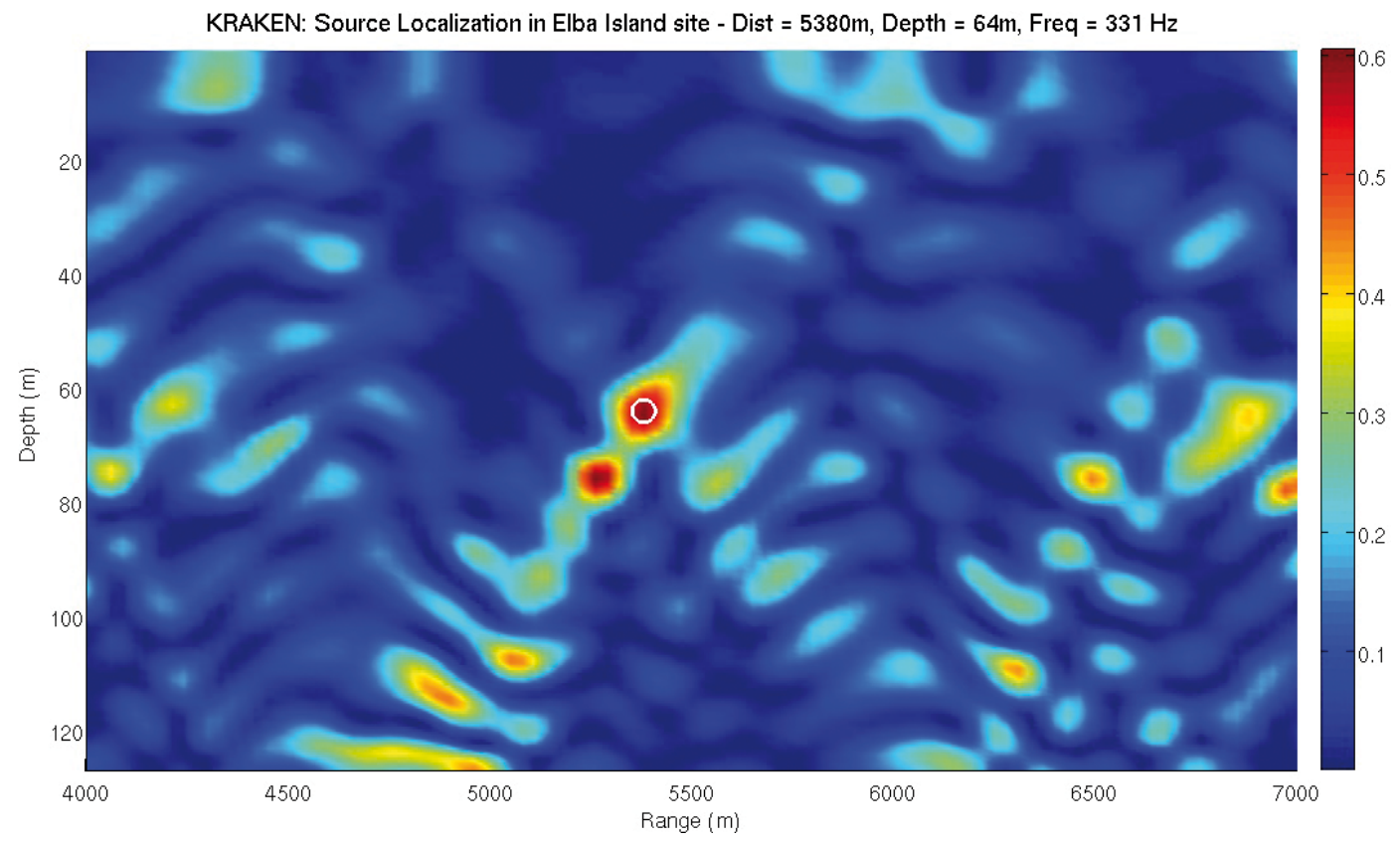

Figure 3 - MFP source localization using experimental data from North Elba Sea Experiment and replicas generated by the KRAKEN model; source frequency is $331 \mathrm{~Hz}$. The white circle indicates the estimated source position.

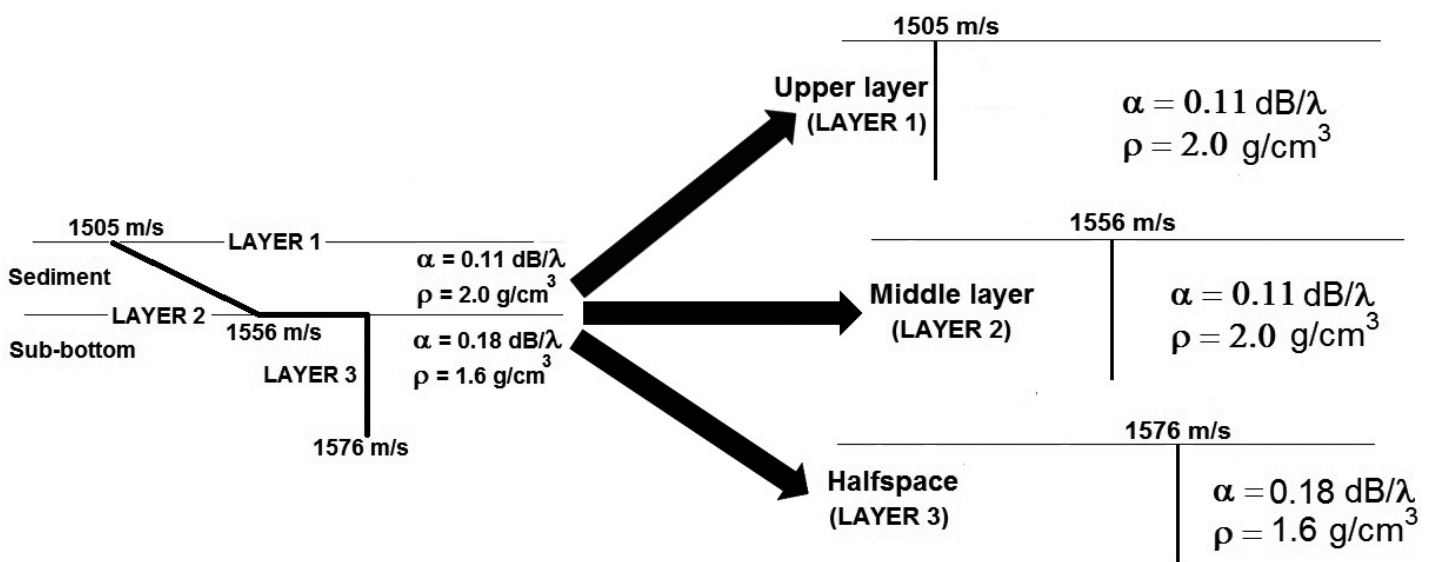

Figure 4 - Multilayer bottom considered with KRAKEN normal mode model (left) and single-layer configurations considered with TRACEO ray tracing model (right).

Table 2 - Bartlett estimator comparing KRAKEN NMM and TRACEO RTM predictions for different configurations of the bottom parameters. The highest values (best agreement) are highlighted in gray.

\begin{tabular}{|c|c|c|c|}
\hline \multirow{2}{*}{ Frequency $(\mathrm{Hz})$} & \multicolumn{3}{|c|}{ Bartlett estimator } \\
\cline { 2 - 4 } & Upper layer & Middle layer & Halfspace \\
\hline 170 & 0.2252 & 0.4515 & 0.5099 \\
331 & 0.1600 & 0.4442 & 0.4029 \\
\hline
\end{tabular}

middle layer (blue) or the halfspace (black), while at $331 \mathrm{~Hz}$ the estimator exhibits different trends depending on the choice of layer; a common feature of the curves is that replacement of the multilayered environment with the upper layer (green) provides the worst match. The reason for this is believed to be due to the low contrast in properties between the water column and the upper layer. A bottom with the properties of this layer would be very absorbent, inducing a rapid dissipation of ray energy. 
Table 3 - Bartlett estimator comparing KRAKEN NMM and TRACEO RTM predictions for different configurations of the launching beam in TRACEO RTM, including number of rays launched $N_{\theta}$ (with $\theta_{\max }=30^{\circ}$ ). The highest values (best agreement) are highlighted in gray.

\begin{tabular}{|c|c|c|c|}
\hline \multirow{2}{*}{ Frequency $(\mathrm{Hz})$} & \multicolumn{3}{|c|}{ Bartlett estimator, $N_{\theta}$} \\
\cline { 2 - 4 } & Upper layer & Middle layer & Halfspace \\
\hline \multirow{2}{*}{170} & 0.3147 & 0.5437 & 0.5638 \\
& 24 & 152 & 152 \\
331 & 0.2285 & 0.5060 & 0.4253 \\
& 238 & 241 & 124 \\
\hline
\end{tabular}

Bartlett versus launching rays - Layers $1,2 \& 3$ - Freq $=170 \mathrm{~Hz}$, thetamax $=30$
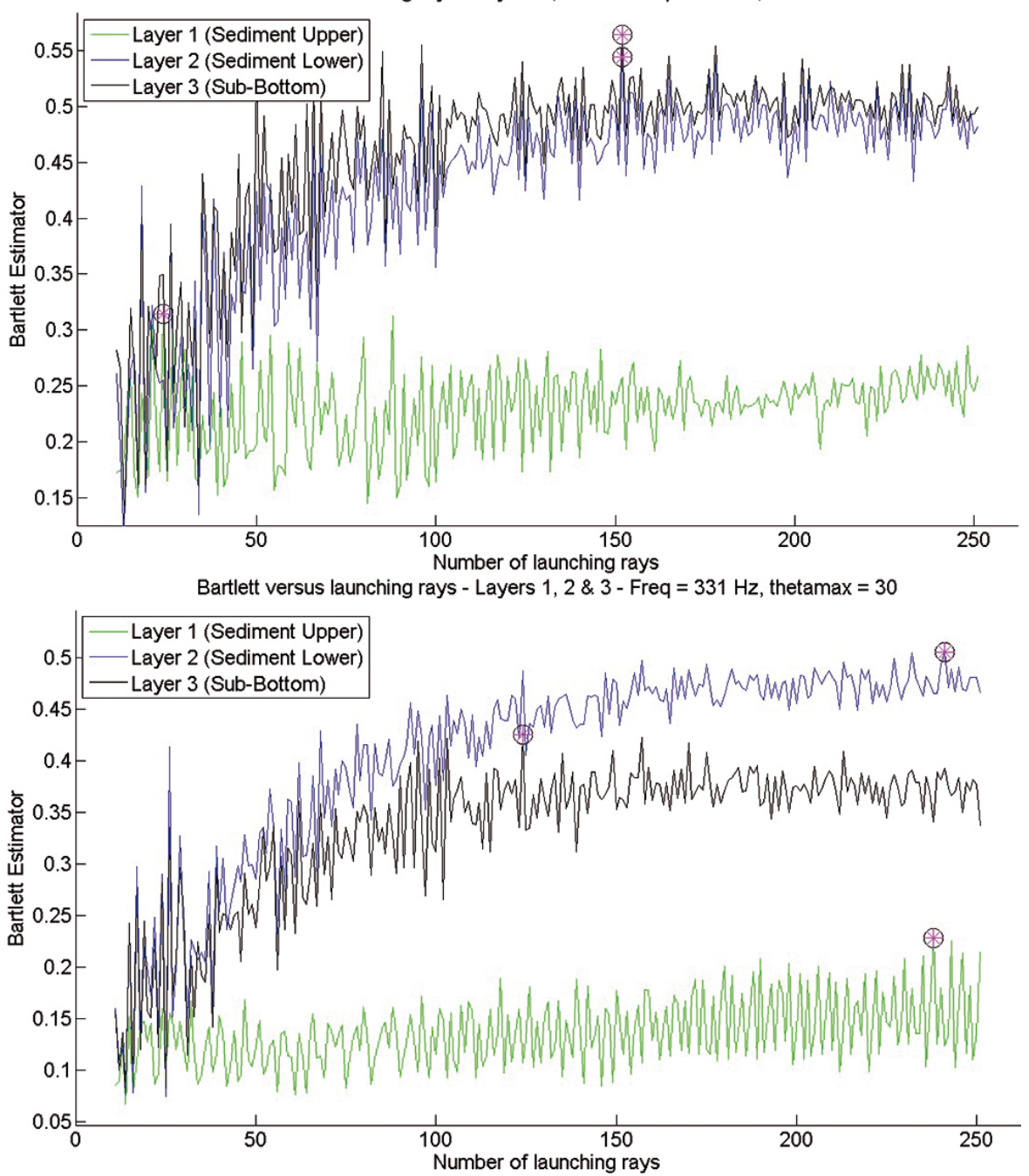

Figure 5 - Bartlett estimator comparing KRAKEN NMM and TRACEO RTM predictions as a function of number of launching rays $N_{\theta}$ for $170 \mathrm{~Hz}$ (upper panel) and $331 \mathrm{~Hz}$ (lower panel). In both cases the asterisk highlights the highest value (best agreement) for each single-layer configuration.

A more robust approach to the issue of the equivalent environment consisted in the optimization of the Bartlett estimator for different combinations of bottom properties at $331 \mathrm{~Hz}$. This was particularly demanding from a computational point of view since it relied on 36 different values of compressional wave speed, 36 values of bottom density and 36 values of compressional wave attenuation, leading to a total of 46656 TRACE0 predictions (shear properties were not included in the optimization). 
Table 4 - Bottom geoacoustic properties that optimize the match between KRAKEN NMM and TRACEO RTM predictions considering, in TRACEO RTM, $N_{\theta}=241$ launching rays and $\theta_{\max }=30^{\circ}$.

\begin{tabular}{|c|c|c|c|c|}
\hline $\begin{array}{c}\text { Source } \\
\text { frequency }\end{array}$ & $\begin{array}{c}\text { Bartlett } \\
\text { estimator }\end{array}$ & $\begin{array}{c}\text { Compressional } \\
\text { velocity }(\mathrm{m} / \mathrm{s})\end{array}$ & $\begin{array}{c}\text { Density } \\
\left(\mathrm{g} / \mathrm{cm}^{3}\right)\end{array}$ & $\begin{array}{c}\text { Compressional } \\
\text { attenuation }(\mathrm{dB} / \lambda)\end{array}$ \\
\hline $331 \mathrm{~Hz}$ & 0.6395 & 1559 & 2.7 & 0.00 \\
\hline
\end{tabular}

Compressional speed was defined in an interval from 1541 to $1576 \mathrm{~m} / \mathrm{s}$, density from 1.0 to $4.5 \mathrm{~g} / \mathrm{cm}^{3}$, and compressional attenuation from 0 to $0.35 \mathrm{~dB} / \lambda$. The results of optimization are shown in Table 4, and indicate that the exhaustive search over the cube of parameters allows in fact to achieve higher values of the Bartlett estimator.

The parameters shown in Table 4 were used for an additional test of optimization, namely, by considering 48 different values of $\theta_{\max } \times 236$ different $N_{\theta}$, leading to 11328 TRACEO predictions at $331 \mathrm{~Hz}$. The resulting ambiguity surface is shown in Figure 6 , and indicates that the best agreement between TRACEO 0 and KRAKEN can be found at $\theta_{\max }=16^{\circ}$ and $N_{\theta}=143$ rays.

The ambiguity surface shown in Figure 6 exhibits an interesting pattern of striations, for which constant values of the Bartlett estimator establish a correlation between $\theta_{\max }$ and $N_{\theta}$. Another interesting aspect of the surface corresponds to the fact that rays with large apertures do not contribute significantly to improve the match between TRACEO and KRAKEN. This can be explained by considering that above a given aperture the increase of bottom interactions induce such a loss of energy, that addi- tional rays do not contribute significantly to the acoustic field. This optimization result agrees with the well known fact that longrange propagation is dominated by small propagation angles since high-angle energy is rapidly attenuated due to bottom loss (Jensen et al., 2011).

These values of $\theta_{\max }$ and $N_{\theta}$ found previously were used for an additional exploration of the Bartlett cube. An additional set of $36 \times 36 \times 36=46656$ cases was considered for further calculations of the Bartlett estimator as a function of bottom density, bottom compressional wave speed and bottom wave attenuation. Values for compressional speed were in the interval between 1550 and $1585 \mathrm{~m} / \mathrm{s}$, for density between 0.7 and $4.2 \mathrm{~g} / \mathrm{cm}^{3}$, and for compressional attenuation between 0 and $0.35 \mathrm{~dB} / \lambda$. Cube slices along the global maximum are shown in Figure 7.

Unlike the striations previously shown in Figure 6, the slices of the Bartlett cube in Figure 7 do not reveal particular correlations between bottom parameters. Results for the highest value of the Bartlett estimator are shown in Table 5.

The main issues regarding the choice of an equivalent environment can be considered complete in order to proceed with

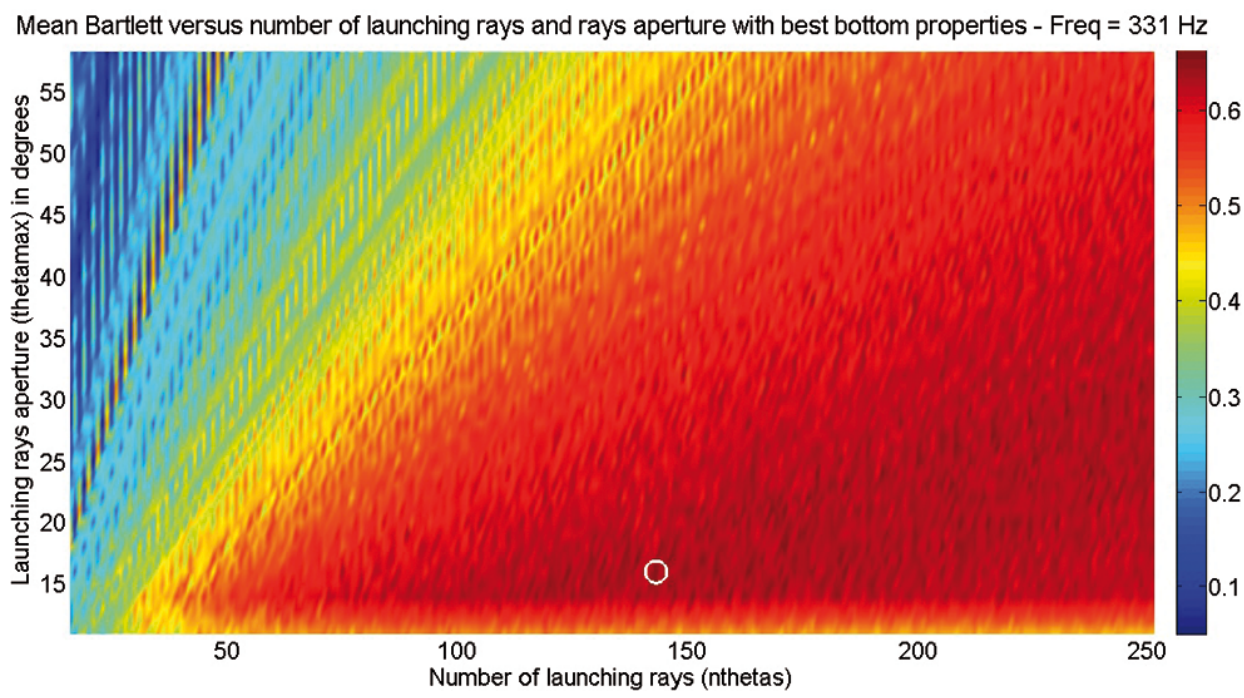

Figure 6 - Bartlett estimator comparing KRAKEN NMM and TRACEO RTM predictions at $331 \mathrm{~Hz}$ as a function of number of launching rays $N_{\theta}$ and ray aperture $\theta_{\max }$ and considering bottom properties specified in Table 4; the white circle highlights the position of the highest value (best agreement). 


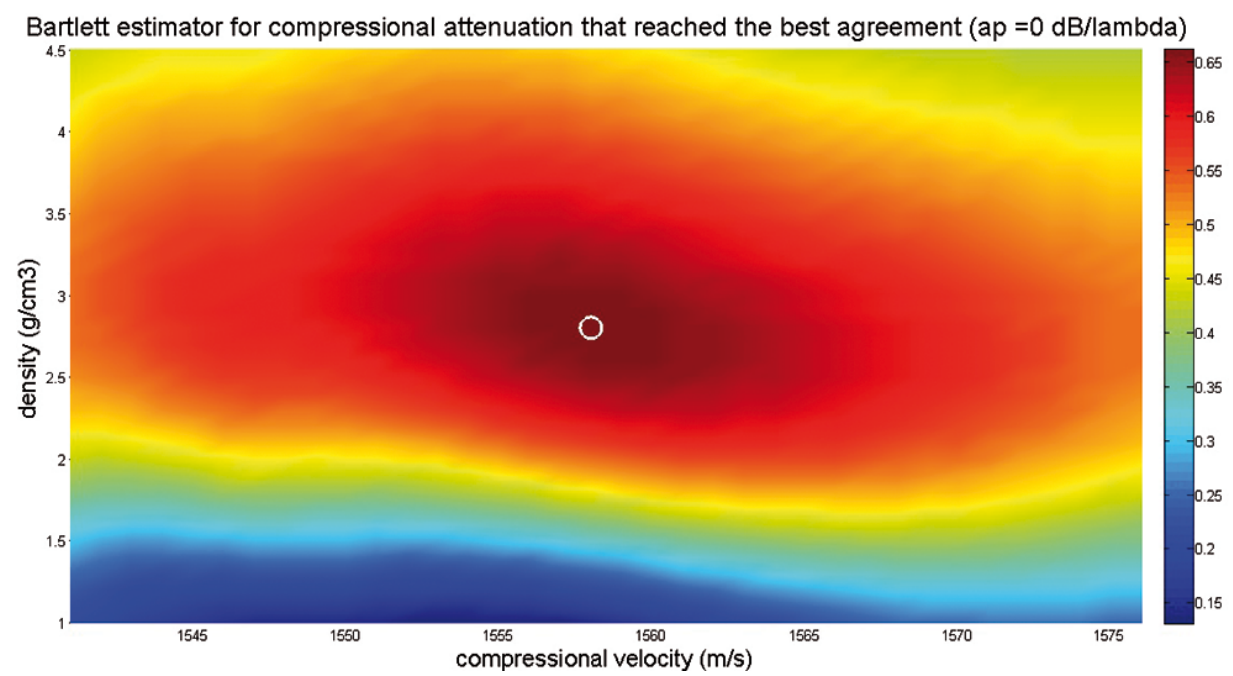

Bartlett estimator for compressional velocity that reached the best agreement $(\mathrm{cp}=1558 \mathrm{~m} / \mathrm{s})$
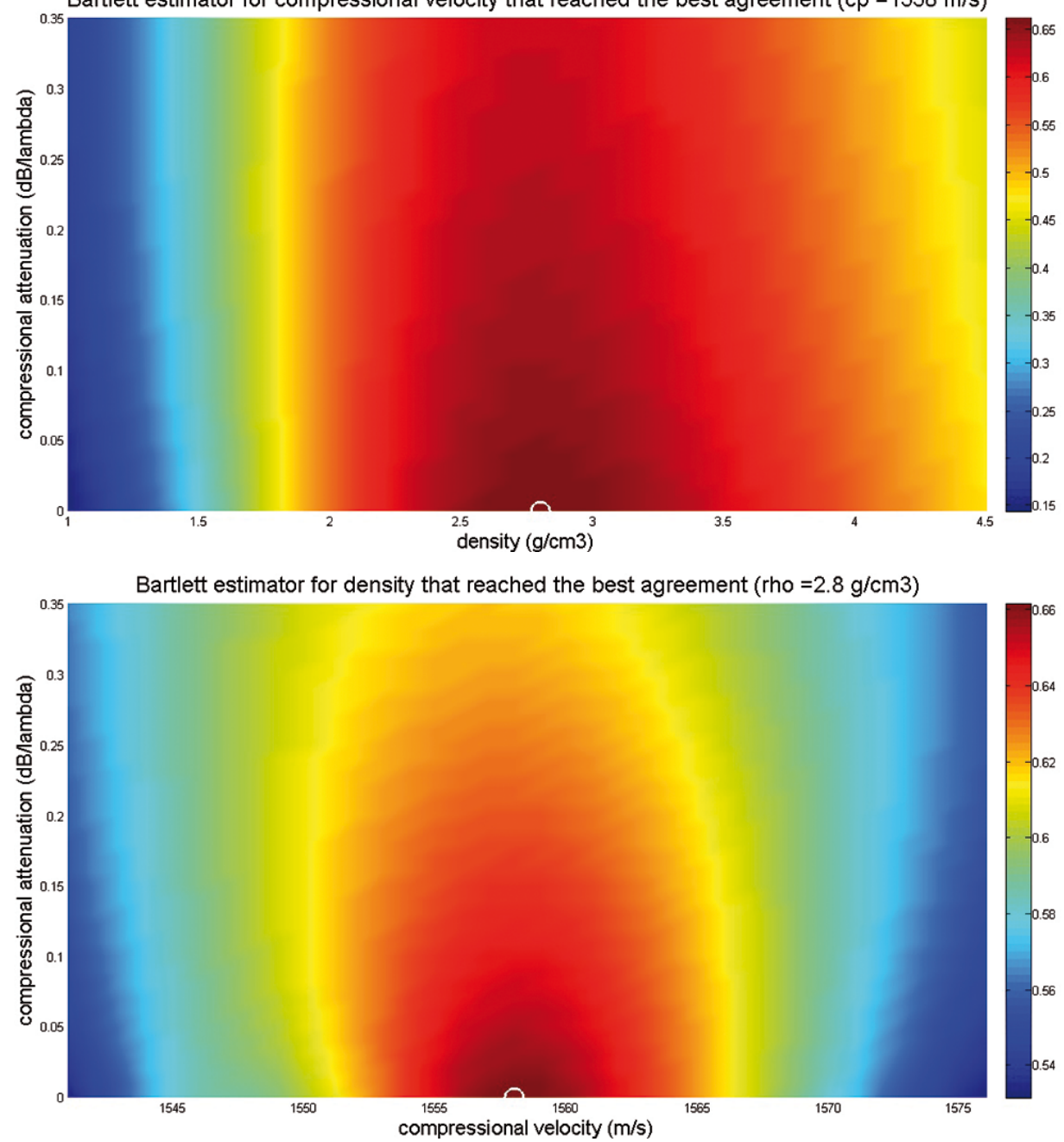

Figure 7 - Slices of the Bartlett cube at $331 \mathrm{~Hz}$ for constant attenuation, $\alpha_{p}=0 \mathrm{~dB} / \lambda$ (upper panel), constant compressional speed, $c_{p}=1558 \mathrm{~m} / \mathrm{s}$ (middle panel), and constant density , $\rho=2.8 \mathrm{~g} / \mathrm{cm}^{3}$ (lower panel). In each case the white circle highlights the position of the best match. 
Table 5 - Bottom geoacoustic properties that optimize the match between KRAKEN NMM and TRACEO RTM predictions considering, in TRACEO RTM, $N_{\theta}=143$ launching rays and $\theta_{\max }=16^{\circ}$.

\begin{tabular}{|c|c|c|c|c|}
\hline $\begin{array}{c}\text { Source } \\
\text { frequency }(\mathrm{Hz})\end{array}$ & $\begin{array}{c}\text { Bartlett } \\
\text { estimator }\end{array}$ & $\begin{array}{c}\text { Compressional } \\
\text { velocity }(\mathrm{m} / \mathrm{s})\end{array}$ & $\begin{array}{c}\text { Density } \\
\left(\mathrm{g} / \mathrm{cm}^{3}\right)\end{array}$ & $\begin{array}{c}\text { Compressional } \\
\text { attenuation }(\mathrm{dB} / \lambda)\end{array}$ \\
\hline $331 \mathrm{~Hz}$ & 0.6614 & 1558 & 2.8 & 0.00 \\
\hline
\end{tabular}

the use of the TRACEO model for source localization. The corresponding discussion is presented in the next section, starting with synthetic data generated with KRAKEN (with and without noise), and ending with the experimental data from the North Elba Sea trial.

\section{Localization with synthetic data}

A set of synthetic "observations" was produced with KRAKEN for North Elba Sea scenery while replicas were generated with TRACEO that uses the equivalent environment. The "observations" were also calculated with TRACEO with replicas calculated with KRAKEN. The results of source localization are summarized in Table 6 .

Table 6 - Source localization results with synthetic data for the conditions of the North Elba Sea experiment (noiseless case).

\begin{tabular}{|c|c|c|c|c|c|}
\hline $\begin{array}{c}\text { Synthetic } \\
\text { data }\end{array}$ & $\begin{array}{c}\text { Replica } \\
\text { generator }\end{array}$ & $\begin{array}{c}\text { Source } \\
\text { range }(\mathrm{m})\end{array}$ & $\begin{array}{c}\text { Source } \\
\text { depth }(\mathrm{m})\end{array}$ & $\begin{array}{c}\text { Total } \\
\text { error }(\mathrm{m})\end{array}$ & $\begin{array}{c}\text { Bartlett } \\
\text { estimator }\end{array}$ \\
\hline KRAKEN & TRACEO & $\begin{array}{c}5266 \\
\text { error: }-3 \mathrm{~m} \\
5269\end{array}$ & $\begin{array}{c}78 \\
\text { error: }+2 \mathrm{~m} \\
76\end{array}$ & 3.61 & 0.6821 \\
KRAKEN & KRAKEN & $\begin{array}{c}5 \\
\text { error: } 0 \\
\text { error: } 0\end{array}$ & 0 & 1 \\
TRACE0 & KRAKEN & $\begin{array}{c}5275 \\
\text { error: }+6 \mathrm{~m} \\
5269\end{array}$ & $\begin{array}{c}76 \\
\text { error: } 0 \\
76\end{array}$ & 6.00 & 0.6020 \\
TRACEO & TRACE0 & $\begin{array}{c}\text { error: } 0 \\
\text { error: } 0\end{array}$ & 0 & 1 \\
\hline
\end{tabular}

Unsurprisingly, the Bartlett estimator achieves its maximal value when the same model is used for the replicas and for the observations. When different models are used the maximal value of the Bartlett estimator lowers, but the errors in position are such that localization can be considered successful. As a reference one can notice that for an idealized range of $5269 \mathrm{~m}$ a total error of $6 \mathrm{~m}$ corresponds to a deviation of just $0.11 \%$ from the expected value.

The case with noise deserves some attention, since the SNR constrains the number of snapshots. In order to discuss this issue, KRAKEN was used to generate the "observations" and the replicas. For a given level of SNR each observation was contaminated with noise using the Box-Muller formula (Porter \& Tolstoy, 1994), and the number of snapshots $(L)$ was increased progres- sively, until localization was successful; this process was repeated for different levels of SNR. To improve the statistical meaning of source localization, a set of 50 model runs was performed; localization was considered successful if the mean of source range and depth was smaller than a given threshold. Additionally, each set of 50 model runs was repeated three times in order to ensure that the final estimate of snapshots was trustful.

The corresponding results are illustrated in Figure 8, which shows that source localization is possible with a small number of snapshots when SNR $>4 \mathrm{~dB}$. For SNR $<4 \mathrm{~dB}$ the number of snapshots tends to increase in an exponential-like manner; in particular using 30 snapshots ensures a successful localization for an $\mathrm{SNR} \approx-10 \mathrm{~dB}$. The dependence could be extended below the value of $-10 \mathrm{~dB}$, expecting to find that the number of snapshots will increase exponentially as SNR decreases. Yet, for practical purposes, such results can become meaningless since snapshots are only useful as long as the environment remains stationary, a key condition that is difficult to find in such a dynamic environment like the ocean.

The SNR value of $-10 \mathrm{~dB}$ was used to contaminate KRAKEN and TRACEO "observations" with noise and 30 snapshots were considered for the calculation of Bartlett estimator. The corresponding results are shown in Table 7 and indicate that localization is possible when the replicas and the observations are generated by the same model. Unfortunately, for the other cases, I0calization is not satisfactory.

Table 7 - Source localization results for the conditions of the North Elba Sea waveguide, considering synthetic data contaminated by noise with SNR $=-10 \mathrm{~dB}$ and number of snapshots, $L=30$.

\begin{tabular}{|c|c|c|c|c|c|}
\hline $\begin{array}{c}\text { Synthetic } \\
\text { data }\end{array}$ & $\begin{array}{c}\text { Replica } \\
\text { generator }\end{array}$ & $\begin{array}{c}\text { Source } \\
\text { range }(\mathrm{m})\end{array}$ & $\begin{array}{c}\text { Source } \\
\text { depth }(\mathrm{m})\end{array}$ & $\begin{array}{c}\text { Total } \\
\text { error }(\mathrm{m})\end{array}$ & $\begin{array}{c}\text { Bartlett } \\
\text { estimator }\end{array}$ \\
\hline KRAKEN & TRACEO & $\begin{array}{c}5042.83 \\
\text { error: }-226.17\end{array}$ & $\begin{array}{c}77.55 \\
\text { error: }+1.55\end{array}$ & 226.18 & 0.0844 \\
KRAKEN & KRAKEN & $\begin{array}{c}5270.29 \\
\text { error: }+1.29\end{array}$ & $\begin{array}{c}75.97 \\
\text { error: }-0.03\end{array}$ & 1.29 & 0.1083 \\
& KRAKEN & 5422.93 & 80.85 & 154.01 & 0.0744 \\
TRACEO & KRrror: +153.93 & error: +4.85 & & \\
& & 5269.12 & 76.02 & 0.12 & 0.1102 \\
TRACEO & TRACEO & $\begin{array}{c}\text { Trror: }+0.12 \\
\text { error: }+0.02\end{array}$ & & \\
\hline
\end{tabular}




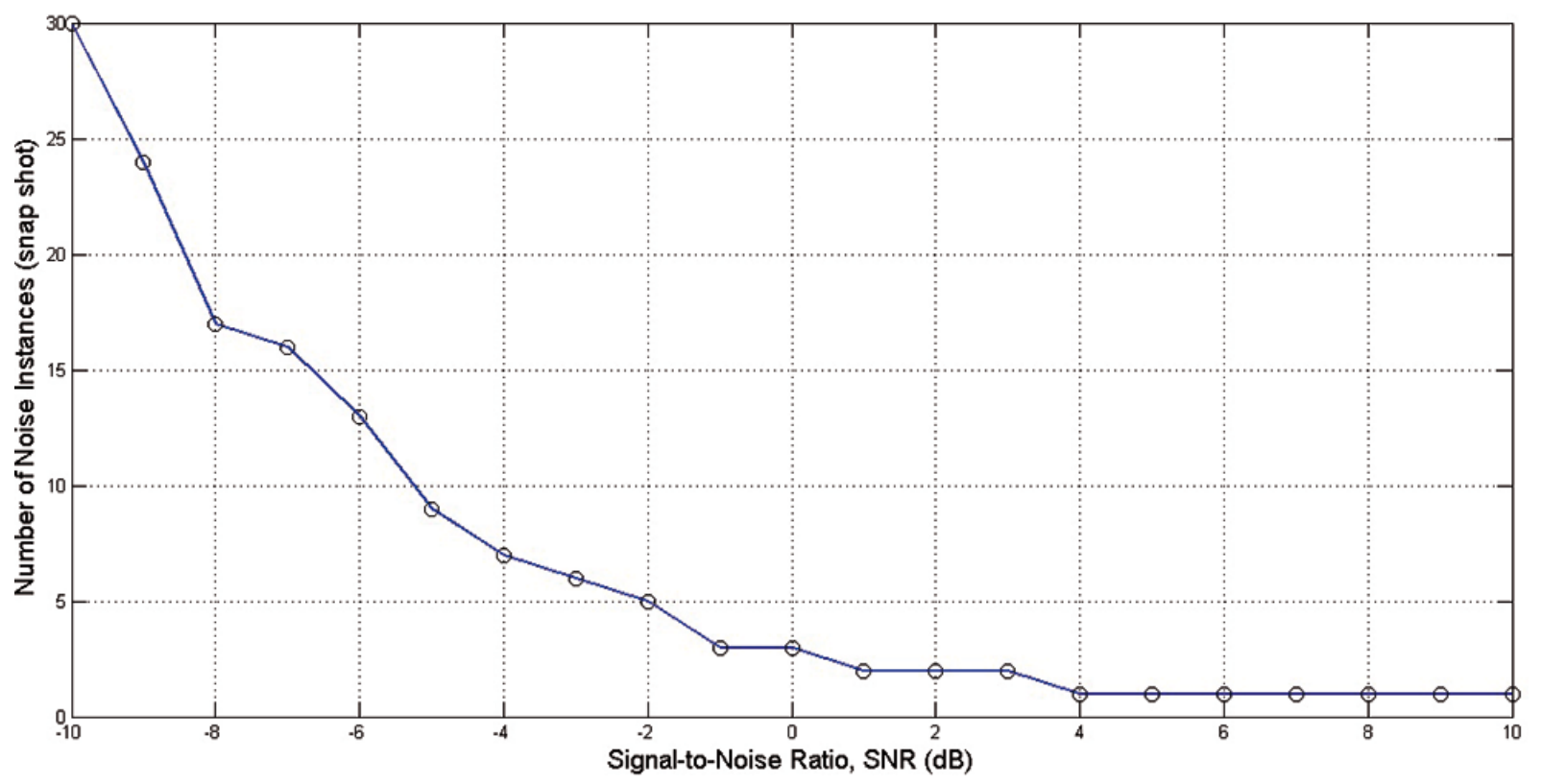

Figure 8 - Number of snapshots $(L)$ required for successful localization as a function of SNR in North Elba Sea scenery.

\section{Localization with experimental data}

Based on KRAKEN results it was considered that the true source position is given by a range of $5269 \mathrm{~m}$ and a depth of $76 \mathrm{~m}$. The TRACEO model was used with the equivalent environment to generate replicas at $331 \mathrm{~Hz}$ for 128 different source depths, and 1000 possible array ranges, spaced 3 meters between 4000 and $6997 \mathrm{~m}$ from the source. Preliminary localization results provided a localization error of around $170 \mathrm{~m}$, indicating that localization was not sufficiently accurate. Yet this result was obtained using a sound speed profile not evenly sampled along depth, something that can introduce unrealistic field artifacts, due to the calculation of inaccurate sound speed gradients. Thus the sound speed profile was evenly interpolated along depth and smoothed and replicas were generated one more time leading to the calculation of the ambiguity surface shown in Figure 9 and the results shown in Table 8.

As shown in Figure 9 and Table 8 the error in source localization was reduced drastically, becoming just $2 \mathrm{~m}$ in depth. It means that a successful source localization can be achieved by using a ray tracing model as replicas generator and experimental results, since an equivalent single-layer environment be used instead of the real multilayered environment.

\section{CONCLUSIONS}

On the basis of the previous discussions the following conclusions can be drawn:
- MFP-based source localization with TRACEO RTM and data from North Elba Sea experiment was found to provide accurate results. Even though localization using KRAKEN normal mode model and multilayered environment provides a high source localization accuracy, corresponding results with TRACEO ray tracing model and an equivalent (single-layered) environment were found to provide also reliable localization results.

- In order to find and equivalent environment for the conditions of the experiment, the Bartlett estimator was used to compare KRAKEN and TRACEO predictions, through direct optimization in the multi-dimensional space of the following parameters:

- Number of rays $N_{\theta}$;

- Semi-aperture of launching beam $\theta_{\text {max }}$;

- Bottom density;

- Bottom compressional wave speed; and

- Bottom compressional wave attenuation.

A fundamental issue of optimization was to rely on an appropriate sampling and smoothing of tabulated sound speed data.

- The equivalent environment was found to be frequencydependent. The optimization values obtained for a given 


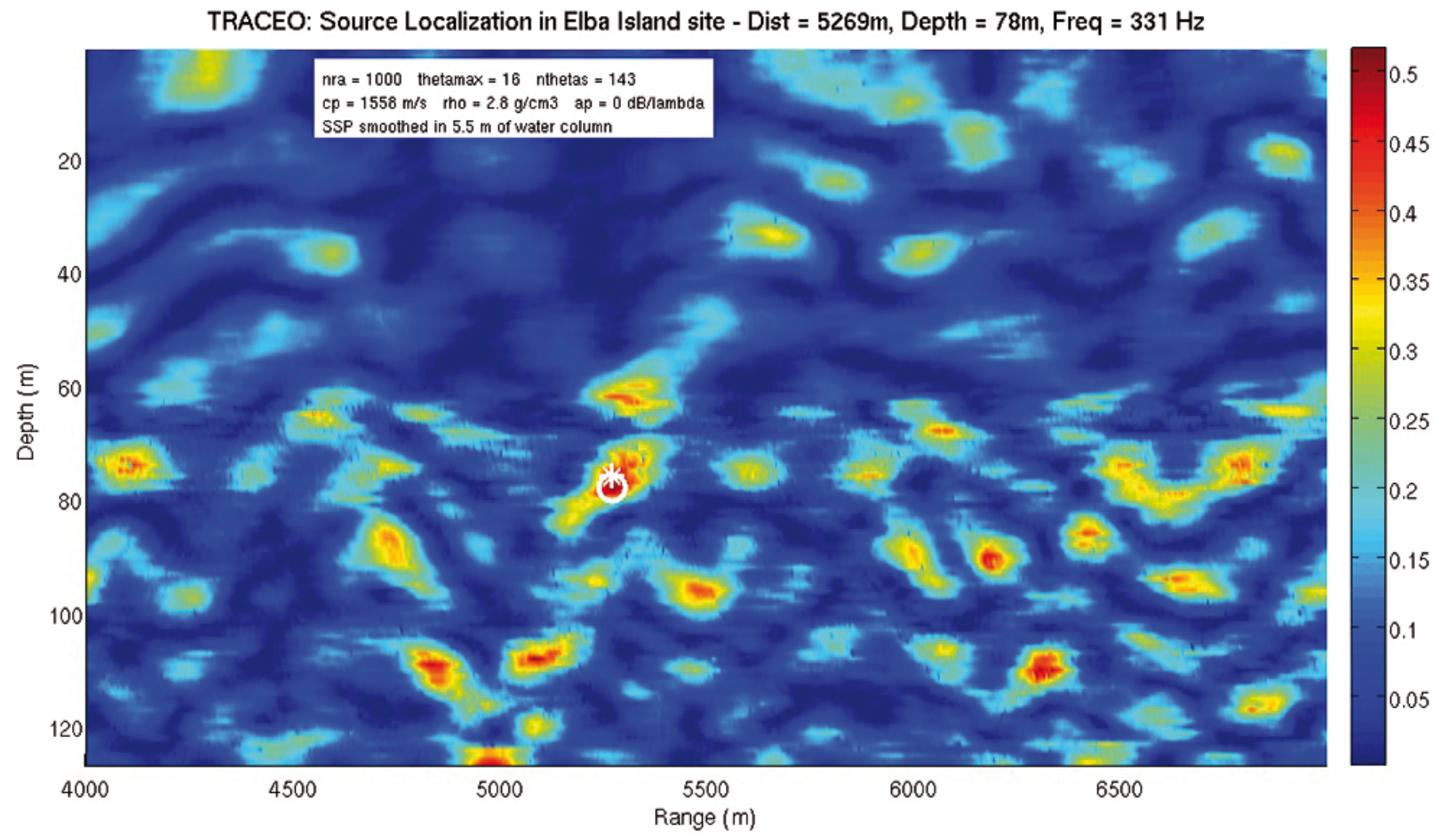

Figure 9 - TRACEO localization results using the equivalent environment and an smoothed sound speed profile.

Table 8 - TRACEO localization results using the equivalent environment.

\begin{tabular}{|c|c|c|c|c|c|}
\hline $\begin{array}{c}\text { Measured } \\
\text { Data }\end{array}$ & $\begin{array}{c}\text { Replica } \\
\text { generator }\end{array}$ & $\begin{array}{c}\text { Source } \\
\text { range }(\mathrm{m})\end{array}$ & $\begin{array}{c}\text { Source } \\
\text { depth }(\mathrm{m})\end{array}$ & $\begin{array}{c}\text { Total } \\
\text { error }(\mathrm{m})\end{array}$ & $\begin{array}{c}\text { Bartlett } \\
\text { estimator }\end{array}$ \\
\hline $\begin{array}{c}\text { North Elba } \\
\text { Sea } \\
\begin{array}{c}\text { Trial } \\
\text { (SACLANT) }\end{array}\end{array}$ & KRAKEN & 5269 & 76 & - & 0.6099 \\
\hline
\end{tabular}

frequency do not necessarily coincide with the values obtained for another frequency. Naturally, the quality of the match improves as frequency increases.

- The issue of data contamination with noise was addressed using simulations, and a dependence of the number of snapshots on SNR levels (which is important for the calculation of the covariance matrix) was obtained.

\section{ACKNOWLEDGEMENTS}

The authors would like to acknowledge Signal Processing Laboratory (SiPLAB)/ University of Algarve, for kindly supporting this work, providing computational resources and facilities. Also, Brazilian Navy and Conselho Nacional de Desenvolvimento Científico e Tecnológico (CNPq), for providing funds to the ac- complishment of a technical and scientific interchange with the University of Algarve.

\section{REFERENCES}

AKAL T, GEHIN C, MATTEUCCI B \& TONARELLI B. 1972. Measured and computed physical properties of sediment cores, Island of Elba zone. SACLANT Undersea Research Centre, SR M-82, La Spezia, Italy.

BAGGEROER AB, KUPERMAN WA \& SCHMIDT H. 1988. Matched-Field Processing: Source localization in correlated noise as an optimum parameter estimation problem. The Journal of the Acoustical Society of America, 83(2): 571-587.

BUCKER HP. 1976. Use of calculated sound fields and matched-field detection to locate sound sources in shallow water. The Journal of the Acoustical Society of America, 59(2): 368-373. 
ETTER PC. 2013. Underwater Acoustic Modeling and Simulation. 4 ed. CRC Press, Boca Raton, 554 pp.

GERSTOFT P \& GINGRAS DF. 1996. Parameter estimation using multifrequency range-dependent acoustic data in shallow water. The Journal of the Acoustical Society of America, 99(5): 2839-2850.

GINGRAS DF. 1994. North Elba sea trial summary [online]. Available on: <spib.rice.edu/spib/saclant.html>. Access on: May 11, 2015.

GINGRAS DF \& GERSTOFT P. 1995. Inversion for geometric and geoacoustic parameters in shallow water: Experimental results. The Journal of the Acoustical Society of America, 97(6): 3589-3598.

HINICH MJ. 1973. Maximum-likelihood signal processing for a vertical array. The Journal of the Acoustical Society of America, 54(2): 499-503.

JENSEN FB, KUPERMAN WA, PORTER MB \& SCHMIDT H. 2011. Computational Ocean Acoustics. Modern Acoustics and Signal Processing. 2 ed. Springer Science \& Business Media, N.Y., 813 pp.

KUPERMAN WA \& LYNCH JF. 2004. Shallow-water acoustics. Physics Today, 57(10): 55-61.

PORTER MB. 1992. The KRAKEN normal mode program (No. NRL/MR/ 5120-92-6920). Naval Research Lab Washington DC.

PORTER MB \& TOLSTOY A. 1994. The Matched-Field Processing benchmark problems. Journal of Computational Acoustics, 2(3): 161185.

RODRÍGUEZ OC, SANTOS P \& JESUS SM. 2009. Modelação acústica submarina de alta frequência baseada em traçamento de raios: revisão teórica e aplicações actuais. In: Encontro de Tecnologia em Acústica Submarina, 8., 2009 (VIII ETAS), Rio de Janeiro, Brazil.

RODRÍGUEZ OC, COLLIS JM, SIMPSON HJ, EY E, SCHNEIDERWIND $J$ \& FELISBERTO P. 2012. Seismo-acoustic ray model benchmarking against experimental tank data. The Journal of the Acoustical Society of America, 132(2): 709-717.

SOARES C \& JESUS SM. 2004. Processamento por ajuste de campo em acústica submarina e aplicações. In: Jornadas do Mar: um Oceano de Oportunidades, Escola Naval, Lisbon, Portugal.

SOARES C, WALDHORST A \& JESUS SM. 1999. Matched-Field Processing: Environmental focusing and source tracking with application to the north Elba data set. In: OCEANS'99 MTS/IEEE. Riding the Crest into the 21st Century, vol. 3, 1598-1602.

TOLSTOY A. 1993. Matched-Field Processing for underwater acoustics. World Scientific, Washington, 212 pp.

WESTWOOD EK. 1992. Broadband matched-field source Iocalization. The Journal of the Acoustical Society of America, 91(5): 2777-2789. 